\title{
Apertura económica y cultivos en el departamento del Meta- Colombia, $1990-2000^{1}$
}

Doi: 10.25100/hye.v14i50.6443

Artículo recibido: 26-04-2017 | Artículo aceptado: 01-12-2017

\section{Luis Fernando Chisnes Espitia}

Profesor vinculado de la Universidad la Gran Colombia, (Colombia). Miembro del grupo de investigación Educación y Pedagogía. Licenciado en Educación Básica con Enfasis en Ciencias Sociales, Universidad Distrital Francisco José de Calda. Magíster en Historia, Universidad de los Andes, (Colombia). Entre sus publicaciones recientes se encuentra: Educación en Ciudadanía. Políticas Públicasy Prácticas Escolares en Bogotá. En: Pensar la educación de América Latina. Sistemas Educativos, Foramción Docente y Convivencia Escolar, Editores: Nilson Javier Ibagón, Dustin Tahsin Gómez y Juliana Santamaría Vargas. Bogotá: Departamento de Publicaciones, Mercadeo y Publicidad, Universidad la Gran Colombia, 2016. Correo electrónico: luis.chisnes@ugc.edu.co

Forma de citar este artículo: Chisnes Espitia, Luis Fernando. "Apertura económica y cultivos en el departamento del Meta- Colombia, 1990-2000". Historia y Espacio, vol. 14, nº 50 (2018): 169-201. Doi: 10.25100/hye.v14i50.6443.

1 Artículo derivado del proyecto de investigación de Maestría en Historia titulado Agricultura en el Meta en la última década del siglo XX. Elementos sociopolíticos de un proceso económico, realizado en la Universidad de los Andes dirigido por la profesora Decsi Arévalo. Artículo de investigación. 


\section{Apertura económica y cultivos en el departamento del Meta- Colombia, 1990-} 2000

Resumen: El proceso que se conoció en Colombia como "Apertura Económica" generó efectos importantes en la organización de la producción, y en las relaciones sociales del departamento del Meta. Este artículo analiza el trasfondo económico de los planes de desarrollo durante la década y cómo influyeron en las decisiones de los agricultores y en su intención de cultivar la tierra. Para ello se realizó una reconstrucción de series estadísticas sobre las áreas cultivadas de los productos más importantes, con base en los datos departamentales, y se analizaron los planes de desarrollo nacionales y del Meta para determinar el énfasis de la política agrícola en el contexto de la apertura. La investigación mostró una afectación negativa a los cultivos semestrales y los de tipo campesino, y un beneficio para los cultivos empresariales que requerían gran inversión de capital.

Palabras clave: política de desarrollo, economía rural, agricultura, historia.

\section{Economic Openness and Crops on the Department of Meta-Colombia, 1990-2000}

Abstract: The process known in Colombia as "Economic Opening" generated important consequences on production organization and social relationships on Meta's Department. This paper seeks to analyze the economic backgrounds of the developments plans along the decade and how this influenced on the farmers decisions and as consequence in their intent to cultivate the land. To do that it was made a crops series reconstruction form the main products, this based in department data, also it analyzed national and Meta's development plans to establish the farming policy emphasis in the openness context. The research showed damage to semester-long as much as to peasantry crops; and a benefit to business crops which required high capital investment.

Keywords: Development Policy, Rural Economy, Agriculture, History. 


\section{Luis Fernando Chisnes Espitia}

\section{Apertura económica y cultivos en el departamento del Meta- Colombia, 1990-2000²}

\section{Introducción}

Los gobiernos nacionales de la década de 1990 establecieron en Colombia una política económica de cambio estructural cuyos objetivos eran lograr, por medio de una mayor exposición al mercado mundial, mejores niveles de producción y productividad, mayor desarrollo de las fuerzas productivas y un manejo coherente de las variables macroeconómicas ${ }^{3}$. Estos objetivos se aplicaron a todos los sectores de la economía, y la agricultura estuvo involucrada. Se buscaba cambiar el paradigma establecido por el modelo de desarrollo guiado por la sustitución de importaciones (ISI) ${ }^{4}$ por uno que estuviera guiado por las exportaciones y el libre mercado.

2 Artículo derivado del proyecto de investigación de Maestría en Historia titulado Agricultura en el Meta en la última década del siglo XX. Elementos sociopolíticos de un proceso económico, realizado en la Universidad de los Andes dirigido por la profesora Decsi Arévalo. Artículo de investigación.

3 Para una descripción más amplia que contraste las políticas del modo de desarrollo por sustitución de importaciones frente al modo de desarrollo guiado por las exportaciones, ver Salomón Kalmanovitz y Enrique López, La agricultura colombiana en el siglo XX (Bogotá: Banco de la República, Fondo de Cultura Económica, 2006); Gabriel Misas, La ruptura de los 90. Del gradualismo al colapso (Bogotá: Universidad Nacional de Colombia, 2002). Álvaro Balcázar, Andrés Vargas y Martha Lucía Orozco, Del proteccionismo a la apertura. ¿El camino a la modernización agropecuaria? (Bogotá: Finagro, Tercer Mundo Editores, IICA, 1999).

4 El modelo de desarrollo conocido como Industrialización por Sustitución de Importaciones fue el enfoque económico más importante en América Latina luego de la Primera Guerra Mundial, aunque su aplicación fue asincrónica en los diferentes países; buscaba suplir la 
En este contexto, es preciso mencionar que esta investigación se centró en el departamento del Meta (Colombia), en la medida en que su economía era principalmente agrícola para el periodo estudiado; de hecho, para inicios del periodo, la participación de este sector en el PIB departamental era del 21.29\%, mientras que la ganadería (actividad considerada más tradicional e importante) representaba el $13.69 \%{ }^{5}$. El departamento no contaba, para el tiempo que cubre la investigación, con una industria consolidada, sino con procesos agroindustriales.

Las investigaciones sobre la apertura han explorado los efectos que tuvo sobre la agricultura. Algunos autores consideran que, efectivamente, hubo una crisis en el sector agrícola ${ }^{6}$, atribuida en mayor medida a los fenómenos climáticos. Las investigaciones se han aproximado al problema desde la economía ${ }^{7}$ a partir de un enfoque neoclásico centrado en las cifras generales del país. En lo relacionado al departamento del Meta, se pueden mencionar autores como García ${ }^{8}$, quien estudió las cifras generales del departamento de manera descriptiva.

Por otro lado, el tema general de la apertura y la liberalización comercial del país han sido objeto de un dinámico debate en los sectores académicos ligados con los debates económicos, y no tanto desde la disciplina histórica. La literatura que analiza la liberalización económica surge (aparece, se produce) casi desde el inicio de la apertura ${ }^{9}$, así como los análisis del proceso, luego de

necesidad de productos escasos por las condiciones políticas de los países de primera industrialización, luego se buscó fomentar la generación de actividades industriales a partir de políticas proteccionistas.

5 Cifras tomadas del Dane. Cuentas departamentales. Archivo Digital.(Completar referencia: título del documento, dirección web, fecha de consulta o acceso, etc.)

6 Carlos Felipe Jaramillo, Crisis y transformación de la agricultura colombiana 1990-2000 (Bogotá: Banco de la República, Fondo de Cultura Económica, 2002).

7 Salomón Kalmanovitz y Enrique López, La agricultura colombiana en el siglo XX (Bogotá: Fondo de Cultura Económica, Banco de la República, 2006).

8 Emilio García Gutiérrez, La apertura y el agro en el Meta 1990-1994 (Santafé de Bogotá: Produmedios, 1995).

9 José Antonio Ocampo y Leonardo Villar, “Trayectoria y vicisitudes de la apertura económica colombiana," Pensamiento Iberoamericano, n. ${ }^{\circ} 21$ (1992): 165-86. 
varios años de estudios centrados en el problema industrial ${ }^{10}$, el comercial $^{11}$ e incluso el género ${ }^{12}$; también se abordan los efectos de este proceso ${ }^{13}$. Estas aproximaciones, aunque académicas, no dejan de estar provistas de unas claras tendencias ideológicas que buscan ya sea defender la apertura o criticarla; operación analítica necesaria en nuestra pretensión de realizar un análisis histórico del fenómeno. Este artículo realiza un análisis histórico de la forma como la política económica se implementó en el Meta y sus consecuentes transformaciones en la producción y en las áreas de cultivos. Así, la investigación se ubica en un cruce entre la historia económica y la historia regional. La reconstrucción histórica se hizo a partir de las cifras desagregadas sobre producción del departamento. Para ello fue necesario contrastar los datos fragmentados de las evaluaciones agrícolas departamentales con las cifras del Ministerio de Agricultura, pues tienden a diferir. Además, se analizó el discurso ${ }^{14}$ económico que marcó la década del noventa en el país y cómo se reflejó en el departamento. Para ello se exploraron los archivos departamentales de la Asamblea del Meta, la Colección Corpes de la Biblioteca Luis Ángel Arango y la Biblioteca del Ministerio de Agricultura. De esta forma, el artículo se basa en una metodología descriptiva y analítica a partir de la reconstrucción de series estadísticas basadas en la documentación disponible, y contrastada con documentos de planeación y política pública.

${ }^{10}$ Luis Fernando López Pineda, “Transformación productiva de la Industria en Colombia y sus regiones después de la apertura económica, Cuadernos de Economía 29, n. . 53 (2010): 239-86.

${ }^{11}$ Jose Jaime Baena Rojas y Xavier Fernández Pons, “Aproximaciones a la inserción de Colombia en el sistema multilateral de comercio en 1995-2015," Análisis Político 29, n. ${ }^{\circ} 87$ (2016): 114-31; Javier Garay, "La política de inserción internacional de Colombia," Nueva Sociedad 231 (2011): 66-78.

${ }^{12}$ Diana Marcela Méndez, "The Impact of Economic Liberalization on Gender Equality in Colombia," CS Ciencias Sociales, n. 15 (2015): 145-71.”type” : “article-journal” \}, “uris” : [ "http://www.mendeley.com/documents/?uuid=fcd92318-d27e-414a-9da7-174446ca0 50c"] \} ], "mendeley" : “formattedCitation": "Diana Marcela M $\backslash$ u00e9ndez, $\backslash u 201 c T h e$ Impact of Economic Liberalization on Gender Equality in Colombia, $\backslash \mathrm{u} 201 \mathrm{~d}<\mathrm{i}>\mathrm{CS}$ Ciencias Sociales $</ \mathrm{i}>$, no. $15(2015$

13 Ricardo Bonilla González, “Apertura y reprimarización de la economía colombiana," Nueva Sociedad 231 (2011): 46-65; Jairo Estrada Álvarez, "Orden neoliberal y reformas estructurales en la decada de 1990: un balance desde la experiencia colombiana," Ciencia Política, n. 1 (2006): 141-78.

${ }^{14}$ Por discurso económico entendemos la narrativa presente en la política económica, los postulados y las formas de justificación. 


\section{Planteamientos del discurso económico nacional}

En la década de 1990 los gobiernos de Colombia se comprometieron con la apertura comercial, lo que hicieron evidente en los planes de desarrollo. Allí consideraron, al igual que los organismos agrupados en lo que se ha conocido como el Consenso de Washington ${ }^{15}$, que las fuerzas productivas se fortalecerían con mayor exposición al mercado mundial. Otro de los argumentos de fondo estaba relacionado con la idea de posicionar al mercado como el ente que debía asignar los recursos en sustitución del Estado, que fue considerado como ineficiente, sesgado a ciertos sectores y productor de mayor desigualdad ${ }^{16}$. Dicho cambio vinculó a todos los territorios de Colombia sin contemplar las características y trayectorias históricas de cada región, lo que generó mayores tensiones en algunos espacios ${ }^{17}$. En específico, los cambios se notaron en el departamento del Meta en variables como la comercialización, los subsidios e incentivos, la asistencia técnica, la financiación y el énfasis de la política pública hacia cultivos comerciales, permanentes, de gran propiedad y de potencial exportador.

El plan de desarrollo titulado La revolución pacífica ${ }^{18}$ rigió entre 1990-94 y buscó alinear el modelo económico de Colombia con las nuevas corrientes mundiales en el campo económico ${ }^{19}$. El plan proponía, entre otras cosas, cambiar el modo de regulación y sintonizar al país con las tendencias mundiales en el manejo macroeconómico, es decir, coordinar las políticas económicas sectoriales con las variables macroeconómicas ${ }^{20}$; tarea en parte adelantada por el Departamento Nacional de Planeación ${ }^{21}$ en lo concerniente a la agricultura.

15 Se destacan instituciones como el Banco Mundial y el Fondo Monetario Internacional.

16 Álvaro Balcázar V., "La agricultura colombiana y las políticas de apertura económica," Coyuntura Agropecuaria 10, n. 3 (1993): 93-104.

17 “Ordenanza n. 023 de mayo 18 de 1995 18. Plan programático de desarrollo Todos somos Meta”, Gaceta del Meta, n. ${ }^{\circ} 1.021$, octubre 13, 1995. Número 1021.

18 Departamento Nacional de Planeación, DNP, Plan nacional de desarrollo 1990-1994. La revolución pacífica, https://colaboracion.dnp.gov.co/cdt/pnd/gaviria_prologo.pdf

19 Ibíd.

${ }^{20}$ Nos referimos a las tasas de interés, la política fiscal y la política cambiaria.

${ }^{21}$. Ministerio de Agricultura y Departamento de Planeación Nacional, Estrategias y políticas para el desarrollo agropecuario (Bogotá: Imprenta Nacional, 1990). 
Todo esto evidencia una correspondencia entre el modelo económico y las premisas del Consenso de Washington ${ }^{22}$.

Como se mencionó, una idea fuerza era la de sustituir al Estado como agente que asignaba los recursos, con el argumento de que en el modelo de desarrollo anterior el Estado había respondido a grupos de presión; en contraste, otros autores consideran que la sustitución implicó solamente el cambio de los grupos de presión a los que el Estado respondía ${ }^{23}$, es decir, que pasó de presiones industriales a presiones financieras. Esta idea en la agricultura se manifestó en el cambio de acción del Estado frente al sector. Este artículo mencionará aspectos como la relación del sector con lo internacional, la relación comercioagricultura y la productividad. No se presume acá que los planes de desarrollo gubernamentales hayan sido aplicados al píe de la letra, sino que, por lo contrario, su aplicación fue conflictiva y llena de tensiones en el territorio, pero se considera que esto influyó en los cultivos del Meta.

\section{Agricultura y lo internacional}

Desde 1990 la planeación económica relacionada con la agricultura, así como la adecuación de tierras, fueron pensadas para fomentar la internacionalización del sector ${ }^{24}$.La financiación priorizó la viabilidad internacional de los proyectos o incluso el aumento de la oferta (agrícola) ${ }^{25}$. La estrategia buscaba reducir la rigidez del sector agrícola, que se le atribuyó al modelo de sustitución de importaciones ${ }^{26}$, y perseguía eliminar las distorsiones ${ }^{27}$ para permitir que la libre competencia y el mercado adecuaran la estructura productiva, pues El

22 John Williamson, "What Washington Means by Policy Reform”, en: Latin American Adjustment: How Much Has Happened?, editado por John Williamson (Peterson Institute for International Economics, 1990), https://piie.com/commentary/speeches-papers/what-washington-means-policy-reform

${ }^{23}$ Gabriel Misas Arango, La ruptura de los 90. Del gradualismo al colapso (Bogotá: Universidad Nacional de Colombia, 2002).

${ }^{24}$ Departamento Nacional de Planeación, DNP, Plan nacional e desarrollo 1990-1994, p 10.

25 Ibíd. p. 12. También señalan que: Tal como lo sugirieron los economistas clásicos, esos son los elementos que en el largo plazo determinan el progreso, la expansión del aparato productivo, y la elevación del nivel de vida de la población.

26 Gabriel Enrique Gómez Ávila, Análisis de la implementación de las políticas neoliberales en Colombia. El caso de la agroindustria comercial de la palma africana, (Bogotá: Colegio Mayor de Nuestra Señora del Rosario, 1996). García Gutiérrez, La apertura y el agro en el Meta 19901994.

${ }^{27}$ Distorsiones como los subsidios y las barreras arancelarias. 
mayor énfasis en los mercados surge de la renovada confianza en sus bondades para asignar recursos económicos más eficientemente que mediante la intervención del $E s t a d o^{28}$. Para ello, desde 1990 se eliminaron los controles de importación y se hicieron proyectos de adecuación de tierras. Esta línea de economía política contrastó con las condiciones del Departamento del Meta, el cual, alejado de los puertos de exportación, había destinado su producción a los centros urbanos del interior del país como Bogotá.

Sin embargo, los departamentos debían vincularse al nuevo modo de desarrollo económico. Es por ello que en los planes de desarrollo departamentales se buscó articular el discurso de la apertura y la globalización con sus propias realidades. El exotismo ${ }^{29}$ fue el argumento bajo el cual los gobiernos departamentales buscaron dicho vínculo, pues La atracción hacia lo exótico en color, olor y sabor que se observa en los habitantes de países desarrollados, es un escenario propicio para el impulso de la experimentación en este campo $^{30}$. Aparecen entonces las ideas de las ventajas comparativas y se apeló a la posibilidad de producir aquello que por clima otros países, con mayores ingresos, no podían.

La crisis del sector agrícola del año 1992 obligó a redireccionar la política de desarrollo agrícola con el cambio de gobierno de 1994; se valoró diferente el papel del Estado, pues el gobierno consideraba que las bases para la apertura de mercados estribaban en una articulación fuerte entre gobierno, empresarios y trabajadores ${ }^{31}$, diferente al primer gobierno de la década. En lo concerniente al sector agrícola en su relación internacional, el plan contempló la especialización y la consecuente explotación de economías de escala como una forma de inserción adecuada a la apertura. En contraste, el gobierno nacional que inició en 1998 (Andrés Pastrana) determinó que no había habido una plena aplicación del modelo de apertura, y que los problemas de la crisis agrícola serían solucionados con la profundización del modelo. Es de notar que no hubo unidad de materia en los sucesivos tres gobiernos del periodo analizado; mientras que el primero

28 Jaramillo, Crisis transformación de la agricultura colombiana 1990-2000, p. 67

${ }^{29}$ Se entiende por exotismo la alusión de los gobiernos departamentales a lo tropical y diferente de los productos propios de los países industrializados y de ingresos altos, a los cuales estaría dirigida su exportación.

${ }^{30}$ Gobernación del departamento del Meta, Plan de desarrollo integral: "Nuestra meta es el Meta" 1993-1997 (Villavicencio: Gobernación del Meta, 1993), p. 34.

${ }^{31}$ Departamento Nacional de Planeación, DNP, Plan nacional de desarrollo 1994-1998. El salto social, https://colaboracion.dnp.gov.co/CDT/CONPES/Econ\%C3\%B3micos/2849.pdf 
y el tercero fueron favorables a la apertura, el iniciado en 1994 tuvo un enfoque centrado en una apertura moderada, más cercano a las tesis de la Cepal.

\section{Productividad y comercialización}

A inicios de la década no había una línea clara sobre las acciones para la productividad aparte de la mención a la necesidad de los distritos de riego en el plan de desarrollo nacional. A nivel departamental, el gobernador problematizó principalmente el tema de las comunicaciones y el acceso a mercados ${ }^{32}$. La alternativa fue planteada a partir de la agroindustria como medio para promover la organización empresarial, elevar la productividad y la eficiencia, reducir costos y generar empleo ${ }^{33}$. Más que la internacionalización, se buscó la inserción nacional y la complementariedad con los mercados fronterizos ${ }^{34}$; la productividad se entendió como especialización.

Hacia 1994, el gobierno de turno enfatizó en las integraciones verticales para aumentar la productividad. Y las acciones relacionadas fueron la producción para el mercado antes que la vocación del suelo, especialización regional para economías de escala, cadenas productivas y la estructura agroempresarial ${ }^{35}$. Ya en 1998 se reformuló la política y se acentuó el énfasis neoclásico en la política agraria y se tomó como referente a las economías asiáticas ${ }^{36}$, al considerar que estas habían aumentado su productividad producto de la exposición al mercado; argumento refutado por Rodrik ${ }^{37}$. Así, el énfasis del gobierno estuvo en la asociación de productores con capitales de inversión ${ }^{38}$.

En relación al comercio, el neoproteccionismo ${ }^{39}$ fue un fenómeno que se hizo evidente en el plan de desarrollo de 1994 e indicaba la existencia de distorsiones en el mercado agrícola internacional. Para contrarrestar este fenómeno, el énfasis de ese gobierno fue generar políticas para promover la producción

${ }^{32}$ Gobernación del Meta, Plan de desarrollo integral, p. 27.

33 Ibíd., p. 92.

34 Ibíd., p. 88.

35 DNP, Plan nacional de desarrollo 1994-1998, Capítulo 6.

${ }^{36}$ Departamento Nacional de Planeación, DNP, Plannacional de desarrollo 1998-2002. Cambio para construirla paz, https://colaboracion.dnp.gov.co/cdt/pnd/pastrana2_contexto_cambio. pdf, p. 29.

${ }^{37}$ Dani Rodrik, "Poor Countries in a Rich World," in The Globalization Paradox. Democracy and the Future of the World Economy (New York, London: Norton, 2011).

38 DNP, Plan nacional de desarrollo 1998-2002, p. 328.

${ }^{39}$ DNP, Plan nacional de desarrollo 1994-1998, Cap. 6, p. 3. 
con destino a mercados con alto poder adquisitivo y frente a los cuales se tuvieran ventajas competitivas ${ }^{40}$. Otra estrategia fue proteger la producción para mercado interno que estaba siendo amenazada por las distorsiones del mercado internacional. De manera que la política económica tuvo tanto rupturas como continuidades que, sumadas a la apertura en general, tuvieron efectos en el comportamiento de la producción agrícola del Meta.

\section{Comportamiento de la producción en el Meta}

Uno de los argumentos a favor de la apertura fue que la agricultura estaba estancada ${ }^{41}$. Sin embargo, al analizar la participación del Meta en el PIB nacional agrícola se observan una participación estable y un crecimiento en el valor de la producción en la década del 80 pasando de 305.718 millones de pesos en 1980 a 2.428 .926 millones en $1989^{42}{ }^{43}$. Lo cual contradice los argumentos del gobierno para justificar la apertura; aunque quiere decir que antes de la apertura era un sector dinámico, innovador y productivo. Se debe tener en cuenta que en el Meta, para esa década, existían tres clases de cultivos: semestrales, anuales y permanentes. Así, las cifras muestran un dinamismo importante en cultivos semestrales como el arroz y la soya, y descensos en sorgo y maíz. En anuales y permanentes se dieron aumentos en cacao y, muy leves, en palma africana. El algodón fue un producto que presentó una gran disminución en este periodo. (Ver Figuras 1-3)

La agricultura del Meta en la década del noventa era una de las actividades principales en términos económicos; sin embargo, había una marginalidad absoluta en relación al uso del suelo. Así, mientras la ganadería aportaba un 13\% al PIB departamental, contaba con la mayoría del área de uso agropecuario, ${ }^{44}$ frente a un 20.2\% del PIB que representaba la agricultura. En el mismo sentido, la agricultura tuvo, a inicios de la década, una participación del 6\% en el valor

${ }^{40}$ Ibíd., p. 14. Algo similar al discurso manejado por el gobernador Baquero y mencionado antes.

${ }^{41}$ Balcázar V., “La agricultura colombiana y las políticas ”, p.115.

${ }^{42}$ Consejo Regional de Planificación Social y Económica de la Orinoquia, Corpes Orinoquia, Diagnóstico integral de la Orinoquia colombiana. Anexo estadístico. Cuadro 10, (Villavicencio: 1993). Colección Corpes, Biblioteca Luis Ángel Arango.

${ }^{43}$ García Gutiérrez, La apertura y el agro en el Meta 1990-1994. Autor que llegó a conclusiones similares.

${ }^{44}$ Departamento Nacional de Estadísticas, Dane, Cuentas departamentales - Colombia (Dane: s.f), archivo digital en la biblioteca del Dane. 
agregado, un valor alto si se tiene en cuenta que solo era superado por el sector petróleo $(7.51 \%)$ y estaba muy por encima de la ganadería $(3,93 \%)$.

Los efectos de la apertura fueron diferentes para los cultivos principales de la región. Los cultivos de ciclo corto o semestrales podían ser tanto de tipo empresarial (arroz, soya, sorgo e incluso el maíz y el algodón) como de economía campesina (maíz y algodón). Por su parte, los cultivos anuales y permanentes tienen también la característica de pertenecer tanto a la agricultura empresarial (palma africana, y en menor medida la yuca y el plátano) como a la agricultura campesina (yuca, plátano, caña, cacao, café). Debido a que no existen registros sistemáticos, ni información adecuada en relación a los cultivos el Meta, se tomaron las cifras del Ministerio de Agricultura de Colombia y los datos existentes de las evaluaciones anuales hechas por el departamento. Como se notará, los datos no son coherentes unos con otros, pero su contraste permite un adecuado acercamiento a los efectos de la apertura económica sobre los cultivos del departamento. Las tablas y gráficas que se presentan más adelante se basan en estas dos fuentes de datos: el Ministerio de Agricultura y documentos de la colección Corpes de la Biblioteca Luis Ángel Arango que contienen datos fragmentados producidos por las autoridades departamentales o consolidados por entidades del Corpes. El contraste en entonces entre una serie completa (la del Ministerio) y una serie fragmentada (la de las fuentes departamentales y Corpes).

\section{Cultivos semestrales}

\section{Arroz}

Cultivo clave para el departamento durante la década de 1990. De este se diferenciaban dos formas de cultivo, arroz secano y arroz riego. La determinación de cada uno estaba mediada por las condiciones físicas, de precipitación pluvial y de infraestructura de riego y drenaje con la que contara el terreno ${ }^{45}$. Sin embargo, a inicios de la década, ambas contaban con similar superficie cultivada ${ }^{46}$. Para 1990 la situación de los arroceros era de

${ }^{45}$ El arroz riego es el que se cultiva mediante sistemas de riego y drenaje. En el arroz secano solo se aprovechan las aguas lluvias de la temporada invernal de los Llanos.

46 Ministerio de Agricultura y Desarrollo Rural, Anuario estadístico del sector agropecuario. 1993-1994 (Santafé de Bogotá: Minagricultura, 1995). 
incertidumbre sobre los procesos de comercialización y de incremento de los $\operatorname{costos}^{47}$.

De esta forma, a inicios de década la superficie de arroz riego se vio disminuida frente a la de arroz secano. Este cultivo tuvo un desempeño bastante irregular durante la década, registrando ascensos y caídas en el área cultivada. Para 1991 se hizo evidente la crisis en el sector. Algunas de las razones de esta crisis eran los

[...] cambios en la gradualidad de algunas medidas de la política económica nacional, el difícil acceso al crédito por considerarse de alto riesgo la inversión y la crisis financiera de la Caja Agraria, la falta de pago oportuno de las principales cosechas, el incremento de las importaciones, el comportamiento de los mercados internacionales especialmente por la caída de precios, las barreras proteccionistas de los países industrializados $[\ldots]^{48}$.

La situación era realmente negativa para los arroceros quienes, al no acceder al pago de sus cosechas, debían buscar financiación en una banca sin capacidad de préstamo. Los cultivadores de arroz riego, debido a esta incertidumbre, no sembraron extensiones similares a las logradas a inicios de 1990, igual decisión tomaron los cultivadores de arroz secano, como se nota en la Figura 1.

${ }^{47}$ Unidad Regional de Planificación Agropecuaria del Meta, Urpa del Meta, Análisis de coyuntura agrícola. Primer semestre 1990. Cultivos semestrales, (Villavicencio: junio de 1990). Colección Corpes, Biblioteca Luis Ángel Arango.

${ }^{48}$ Urpa del Meta, Informe de coyuntura agrícola 1991 B definitiva, preliminar 1992 (Villavicencio: 1992), Colección Corpes, Biblioteca Luis Ángel Arango. 
Figura 1. Cantidad de hectáreas sembradas con arroz riego y secano en el Meta, 1990 - 2000.

\begin{tabular}{|c|c|c|c|c|c|}
\hline Año & $\mid$\begin{tabular}{l|} 
Cifras \\
Minagricultura \\
(Riego)
\end{tabular} & $\mid \begin{array}{l}\text { Cifras } \\
\text { Minagricu ltura } \\
\text { (Secano) }\end{array}$ & Año & $\begin{array}{l}\text { Cifras } \\
\text { departamentales } \\
\text { (Riego) }\end{array}$ & \begin{tabular}{|l} 
Cifras \\
departamentales \\
(Secano)
\end{tabular} \\
\hline 1990 & 57.400 & 57.500 & 1990A & 35.000 & 60.000 \\
\hline 1991 & 47.100 & 46.800 & 1991 & 51.780 & 46.891 \\
\hline 1992 & 52.758 & 43.935 & & & \\
\hline 1993 & 56.483 & 37.036 & & & \\
\hline 1994 & 53.470 & 45.355 & 1995A Def & 23.400 & 36.580 \\
\hline 1995 & 41.766 & 43.094 & 1995B Def & 13.760 & 6.938 \\
\hline 1996 & 38.970 & 40.913 & $\begin{array}{l}\text { 1996A } \\
\text { Pron. }\end{array}$ & 19.700 & 31.280 \\
\hline 1997 & 40.917 & 40.950 & $\begin{array}{l}\text { 1996B } \\
\text { Pron. }\end{array}$ & 13.954 & 7.500 \\
\hline 1998 & 46.770 & 52.450 & $\begin{array}{c}\text { 1997A } \\
\text { Def. }\end{array}$ & 23.158 & 36000 \\
\hline $\begin{array}{l}1999 \\
2000\end{array}$ & $\begin{array}{l}44320 \\
36014\end{array}$ & $\begin{array}{l}61687 \\
70465\end{array}$ & $\begin{array}{c}\text { 1997B. } \\
\text { Preeli }\end{array}$ & 14431 & 2240 \\
\hline
\end{tabular}

Fuente: Anuario estadístico Ministerio de Agricultura Años 1990. 1991, 1992, 1993, 1994, 1995, 1996, 1997, 1998, 1999, 2000, Informes de coyuntura del departamento del Meta. Informe de coyuntura Agrícola 1991 B Definitiva Preliminar 1992 URPA Meta. Gobernación del Meta. Colección Corpes; Cifras del Sector Agropecuario 1995 Ministerio de Agricultura. Secretaría de Agricultura. Departamento del Meta. Villavicencio. Enero de 1996. Colección Corpes, Cifras del Sector Agropecuario 1997A Definitivo. 1997B Preliminar. 1998A Pronóstico, Ministerio de Agricultura. Secretaría de Agricultura. Departamento del Meta. Enero 1998. Villavicencio. Colección Corpes. Cifras del Sector Agropecuario. 1995B Definitivo. Pronóstico 96A. Ministerio de Agricultura, Secretaría de Agricultura. Departamento del Meta, Villavicencio. Colección Corpes)

La crisis del sector arrocero se mantuvo durante la década y el crédito tampoco contribuyó. De hecho, la financiación, bajo la óptica del nuevo modelo (a saber, determinada por el mercado y las instituciones privadas) contribuyó a generar condiciones de iliquidez en la producción. Se implementaron en el Meta otras formas de financiación a través de casas proveedoras de insumos. 
Estas casas comerciales muchas veces estaban adscritas a la industria molinera, o eran las mismas molineras las que entregaban insumos para la producción bajo compromiso de entrega de los productos ${ }^{49}$. Esto hizo que el productor perdiera capacidad de negociación frente a los proveedores.

Solo hacia finales de la década se vieron señales de recuperación, pero solo en el arroz secano. La difícil situación del cultivo más importante del departamento produjo problemas sociales en la medida en que era de campesinos no propietarios, arrendatarios, y que fue sustituido en muchas partes por palma africana ${ }^{50}$, por lo cual los roles del campesinado fueron variando a lo largo de la década. La industria arrocera también fue duramente golpeada por el proceso de apertura por la importación de arroz que pasó de 66 toneladas de arroz blanco en 1990 a 67.963 toneladas en 1992, y a 237.627 toneladas en 1994. El punto máximo de importaciones durante el periodo estudiado fue de 314.165 toneladas en $1998^{51}$, luego del cual hay una caída que coincide con el crecimiento del cultivo en el Meta.

La premisa de la apertura, según la cual la exposición al mercado generaría cambios en la producción, se cumplió parcialmente para el arroz (específicamente para el que contaba con sistemas de riego). La exposición de mercados protegidos a las importaciones de cereales ${ }^{52}$, entre ellos el arroz, posibilitó el debilitamiento de los productores metenses y la consiguiente transformación de cultivos. No obstante, ante la crisis se vio una pequeña respuesta de los productores a las medidas tomadas en el departamento alrededor del control del almacenamiento para evitar caídas de precios en épocas de cosechas. ${ }^{53}$. Los gobiernos no evaluaron la estacionalidad de la

${ }^{49}$ Ministerio de Agricultura y Desarrollo Rural, y Secretaría de Agricultura del. departamento del Meta, Cifras del sector agropecuario 1995 (Villavicencio: enero de 1996), Colección Corpes, Biblioteca Luis Angel Arango.

${ }^{50}$ Ibíd.

${ }^{51}$ Federación Nacional de Arroceros, Fedearroz, Estadísticas arroceras. Importaciones de arroz a Colombia 1990-2000, consultada en 13 de diciembre de 2017, http://www.fedearroz.com. co/new/importaciones.php.

${ }^{52}$ Gustavo Adolfo. Hernández y Juan Ricardo Perilla, "Análisis de las importacione agropecuarias en la década del 90" (Bogotá: Departamento Nacional de Planeación, Dirección de Estudios Económicos. 2001).

${ }^{53}$ Ministerio de Agricultura y Desarrollo Rural, y Secretaría de Agricultura del. departamento del Meta, Cifras del sector agropecuario 1997A definitivo. 1997B preliminar. 1998A pronóstico (Villavicencio: enero 1998), Colección Corpes, Biblioteca Luis Ángel Arango. 
producción agrícola, y las caídas de precios fueron un riesgo constante para los productores.

\section{Maíz}

El maíz era un cultivo que estaba adquiriendo una importancia determinante en el Meta, pues el área destinada para su cultivo venía creciendo de manera importante. A finales de la década del 80 este cultivo mostraba un dinamismo destacado. La tendencia creciente estaba estimulada por la inclusión del mismo en la dieta del departamento ${ }^{54}$. El área cultivada crecía en promedio en un $500 \%$ en la segunda mitad de la década del $80^{55}$. La importancia del cultivo se debía a que para los pequeños y medianos agricultores de las vegas de los ríos Ariari, Guayabero, Meta y Upía, entre otros ${ }^{56}$ era un cultivo base de la actividad económica. Al entrar en la década del 1990 se distinguen dos formas de producción: maíz tradicional y maíz tecnificado.

Este producto, cuyo destino eran los mercados cercanos y Bogotá, no tuvo las trabas comerciales del arroz, elemento que explica por qué no se vio expuesto a las presiones del mercado abierto en la primera mitad de la década. El maíz pasó a régimen de libre importación en $1991^{57}$, pero el cultivo no se vio amenazado, ya que su mercado era local, ante que nacional; paradójicamente la ausencia de vías garantizó su estabilidad; aunque no haya habido en la década estudiada un crecimiento como el de finales de los años ochenta.

La relativa estabilidad que presentó este cultivo en la primera mitad de la década no implicó, necesariamente, su fortaleza. Teniendo en cuenta que, en estos primeros años del periodo estudiado, los gobiernos impusieron los mayores cambios en la agenda política agrícola, los cultivadores encontraron trabas para su desarrollo. De esta forma, hacia 1995 se nota cómo las medidas propiciadas por el gobierno anterior [1990-94], que prácticamente terminaron por excluir la asistencia técnica agropecuaria particular en el campo, ya empiezan a mostrar sus funestas consecuencias ${ }^{58}$. Esto explica el porqué del desarrollo deficitario del cultivo del maíz tecnificado en la segunda mitad de la década.

\footnotetext{
${ }^{54}$ Urpa del Meta, Análisis de coyuntura aǵrícola. Primer semestre 1990.

${ }_{55}$ Ibíd.

56 Ibíd.

57 Departamento Nacional de Planeación (DNP Umacro, Uda) y Ministerio de Agricultura y Desarrollo Rural, "Instrumento de franjas de precios para la importación de productos agrícolas y subproductos seleccionados”, Documento DNP 2511 (Bogotá: febrero 1991).

58 Ministerio de Agricultura, Cifras del sector agropecuario 1995, s. p...
} 
Ante la crisis de la agricultura y los constantes cambios en la política económica, los agricultores se encontraron en constante incertidumbre, reflejada en la disminución del área cultivada en la segunda mitad de la década; reducción que se hizo evidente en el maíz tecnificado (el cual requería mayor inversión), como se muestra en la Figura 2. Parte de las causas fueron las masivas importaciones que, después de cinco años, llegaron a la puerta de los agricultores del Meta ${ }^{59}$. El maíz tradicional se mantuvo en parte porque su cultivo seguía siendo fundamental en el proceso de colonización de tierras mediante la quema y la siembra. La apertura y la exposición al mercado, en el mediano plazo, llevaron a la marginalización de la producción tecnificada del maíz y, de cierta forma, a fomentar la ampliación de la frontera agrícola en el Meta.

Figura 2. Cantidad de hectáreas sembradas con maíz tradicional y tecnificado en el Meta.

\begin{tabular}{|c|c|c|c|c|c|}
\hline Año & \begin{tabular}{l|l} 
Cifras \\
Minagricultura \\
(Tradicional) \\
\end{tabular} & \begin{tabular}{|l|} 
Cifras \\
Minagricultura \\
(Tecnificado) \\
\end{tabular} & Año & \begin{tabular}{|l|} 
Cifras \\
departam entales \\
(Tradicional) \\
\end{tabular} & \begin{tabular}{|l} 
Cifras \\
departamentales. \\
(Tecnificado)
\end{tabular} \\
\hline 1990 & 12.600 & 12.200 & $1990 \mathrm{~A}$ & 8.830 & 10.725 \\
\hline 1991 & 9.400 & 15.400 & 1991 & 13.595 & 16.421 \\
\hline 1992 & 12.385 & 9.525 & & & \\
\hline 1993 & 12.654 & 10.189 & 1995A & & \\
\hline 1994 & 15.476 & 13.299 & \begin{tabular}{|l|} 
Def. \\
1995B
\end{tabular} & 6.175 & 5.199 \\
\hline 1995 & 10.864 & 10.540 & \begin{tabular}{|l} 
Def. \\
1996A
\end{tabular} & 4.280 & 2.582 \\
\hline 1996 & 12.076 & 6.417 & $\begin{array}{l}\text { Pron. } \\
\text { 1996B }\end{array}$ & 6.388 & 5.031 \\
\hline 1997 & 14.095 & 6.208 & $\begin{array}{l}\text { Pron. } \\
\text { 1997A }\end{array}$ & 3.080 & 1.500 \\
\hline 1998 & 13.473 & 4.793 & \begin{tabular}{|l|} 
Def. \\
1997B.
\end{tabular} & 10.345 & 4.168 \\
\hline 1999 & 11.647 & 5.828 & Preeli & 4.195 & 1.812 \\
\hline 2000 & 8.824 & 8.882 & & & \\
\hline
\end{tabular}

Fuente: Anuario estadístico. Ministerio de Agricultura Años 1990. 1991, 1992,1993, 1994, 1995, 1996, 1997, 1998, 1999, 2000, Informes de coyuntura del departamento del Meta. Informe de coyuntura Agrícola 1991 B Definitiva Preliminar 1992 URPA Meta. Gobernación del Meta. Colección Corpes; Cifras del Sector Agropecuario 1995 Ministerio de Agricultura. Secretaría de Agricultura. Departamento del Meta. Villavicencio. Enero de 1996. Colección Corpes, Cifras del Sector Agropecuario 1997A Definitivo. 1997B Preliminar. 1998A Pronóstico, Ministerio de Agricultura. Secretaría de Agricultura. Departamento del Meta. Enero 1998. Villavicencio. Colección Corpes. Cifras del Sector Agropecuario. 1995B Definitivo. Pronóstico 96A. Ministerio de Agricultura, Secretaría de Agricultura. Departamento del Meta, Villavicencio. Colección Corpes)

${ }^{59}$ Ministerio de Agricultura y Desarrollo Rural, y Secretaría de Agricultura del. departamento del Meta, Cifras del sector agropecuario. 1995B definitivo. Pronóstico 96a (Villavicencio: junio 1996), Colección Corpes, Biblioteca Luis Ángel Arango. 
Así como el arroz y el maíz eran predominantes en un semestre, su cultivo estaba complementado por otros de ciclo corto para completar el año. En el Meta fueron principalmente soya y sorgo.

\section{Soya}

La soya fue promovida para el segundo semestre del año en la década del ochenta y recibió importante apoyo y financiación tanto del Estado como de los agentes privados ${ }^{60}$, dado que ayudaba a mejorar los suelos para el cultivo de arroz. Entonces, era una siembra que complementaba de muy buena manera al principal cultivo del departamento. Así, la soya inició la década de apertura con un dinamismo importante. Más de 30 mil hectáreas cultivadas, tanto en 1990 como en 1991, auguraban un futuro promisorio. Sin embargo, esta bonanza inicial se vio frenada rápidamente. Para 1992 los cultivadores redujeron la superficie a menos de la mitad de lo que había alcanzado en los dos años anteriores ${ }^{61}$.

Este producto compitió con las importaciones pues era materia prima industrial, y muy tempranamente enfrentó tanto el desestímulo por parte del gobierno como las prácticas de pago inoportuno que afectaron a los productores $^{62}$. De hecho, el cultivo fue el primero en el Meta que se vio seriamente afectado por las medidas tomadas a partir del cambio de modo de desarrollo. La exposición al mercado en virtud de la internacionalización, la rebaja de aranceles y subsidios, como parte constitutiva del modo de regulación, y el régimen de acumulación actuaron de manera evidente en la soya y en lo que se pensaba que debía hacerse frente a ella, pues:

Considerando la tendencia descendente de las oleaginosas en el mercado mundial, que no se espera cambie sustancialmente en el inmediato futuro, las posibilidades del cultivo de la soya en el país se estrechan considerablemente teniendo en cuenta el ritmo continuo de incremento de los costos. Las mejores opciones futuras para el desarrollo del cultivo

60 Secretaría de Agricultura, Ganadería y Desarrollo del departamento del Meta, El desarrollo agrícola en el Meta y la reciente coyuntura (Villavicencio: 1989), Colección Corpes, Biblioteca Luis Ángel Arango.

${ }^{61}$ Ver Gráfico 1.

${ }^{62}$ Unidad Regional de Planificación Agropecuaria del Meta, Urpa del Meta, Informe de coyuntura agrícola. 1991 B definitiva. Preliminar 1992. Cuadro 2 (Villavicencio:1992), s. p. 
quedan bajo expectativas de importante transformaciones en la tecnología del cultivo $[\ldots]^{63}$.

Esto permite ver cómo la ideología del modelo de desarrollo consideraba que la exposición al mercado llevaba necesariamente a cambios tecnológicos. Bajo esta premisa, las dificultades que estaban experimentando los productores de soya a partir de su exposición al mercado podían solucionarse solo a partir del cambio tecnológico. Esto, sin embargo, no contempló que el Estado venía reduciendo capacidad en la asistencia técnica hacia los agricultores. La tecnología y la maquinaria especializada eran vistas como la alternativa para las dificultades.

Figura 3. Trayectoria de la soya en el Meta en hectáreas.

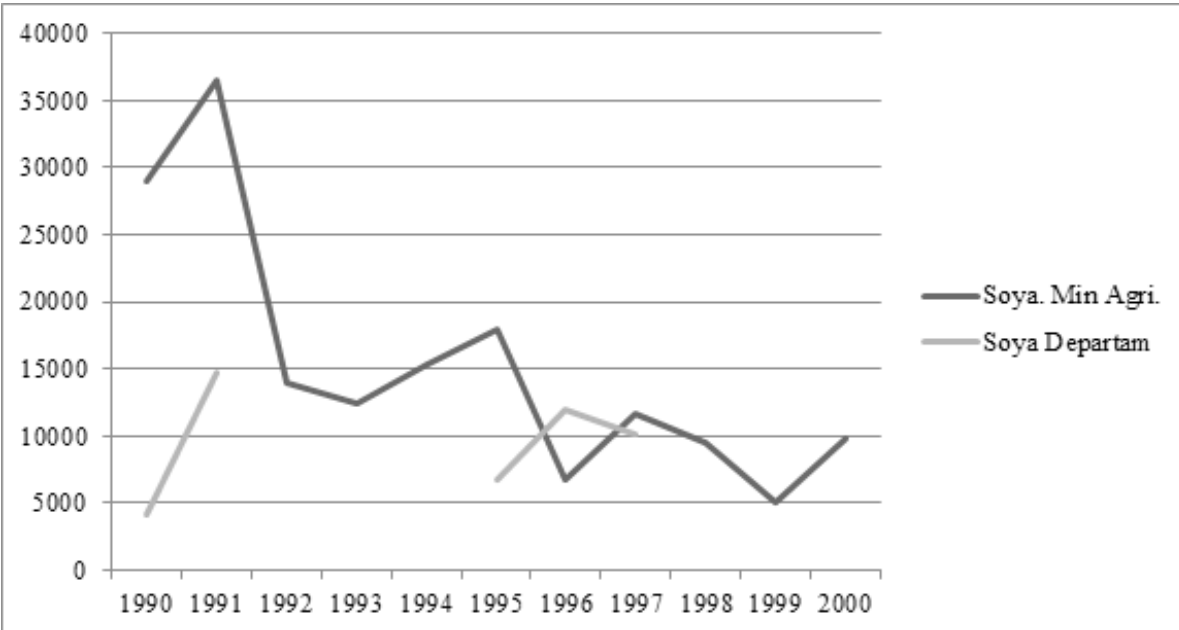

Fuente: Anuario estadístico Ministerio de Agricultura e informes de coyuntura del departamento.

Los productores de soya, que también cultivaban arroz, continuaron con la actividad. En parte motivados por el hecho de que era un cultivo sustituto para el segundo semestre del año. Hacia mediados de la década las áreas de producción venían reduciéndose de manera consecutiva, lo que indica que el dinamismo de la siembra no fue sostenible a mediano plazo.

Además de lo anterior, los riesgos de la inversión y la ausencia de un norte en la política les dificultaron a los agricultores generar y planear sus propias

${ }^{63}$ Urpa del Meta, Informe de coyuntura agrícola. 1991 B definitiva. Preliminar 1992, s. p. 
inversiones ${ }^{64}$. De hecho, la participación del gobierno en la agricultura a mediados de la década, especialmente en la soya, se limitó a advertir sobre lo inconveniente de su cultivo. El gobierno en 1995 advirtió que no se sembrara soya en el departamento debido a los problemas de comercialización de la cosecha anterior; problemas que se debieron al ingreso de grandes volúmenes procedentes de Bolivia y Estados Unidos ${ }^{65}$. Esto muestra que el interés del gobierno era desestimular la producción, pero no se ofrecieron alternativas para sustituir el producto. Sin embargo, los cultivadores sembraron, aunque con un área notablemente menor a la del año anterior. (Figura 3)

Hacia los años 1997 y 1998 las medidas tomadas por el ministerio y los industriales en relación a la comercialización, y la aclaración de las reglas de juego permitieron reactivar levemente el cultivo (no a los niveles previos a la apertura). Estas acciones no tuvieron una respuesta a mediano plazo y con el cambio de gobierno nacional se evidenció nuevamente un descenso del área cultivada. Las prácticas cotidianas de comercialización afectaron a los productores que vieron disminuir año a año el área cultivada debido a las incertidumbres de una producción expuesta al mercado y comercializada, en lo interno, bajo prácticas diferentes a las que se establecían en la teoría de modo de regulación de apertura.

\section{Sorgo}

El sorgo se sembró como un cultivo de último momento; no estaba dentro de las prioridades de los agricultores y se sembraba cuando las fechas de los demás cultivos semestrales de segundo semestre habían pasado. Por lo tanto, su importancia fue marginal respecto a productos como la soya o el algodón. De hecho, el cultivo del sorgo respondía a las señales del algodón y la soya. Esto significaba que, cuando las condiciones eran adversas para los cultivos de soya y algodón, y habiéndose preparado la tierra, los productores decidían como última instancia la siembra del sorgo. Dado que se afrontaba una difícil situación para la soya, se podrían esperar mejores resultados para el sorgo en el departamento durante la apertura.

Este cereal se incluyó, a inicios del periodo analizado, en el instrumento de franjas de precios. Sin embargo, ya desde inicios de la década se estaba

${ }^{64}$ Ministerio de Agricultura, Cifras del sector agropecuario 1995, s. p.

${ }^{65}$ Ministerio de Agricultura, Cifras del sector agropecuario. 1995B definitivo. Pronóstico 96A, p. 6. 
diagnosticando la caída en el área cultivada ${ }^{66}$. De hecho, la caída fue sostenida durante los diez años (Figura 4), reafirmando lo que en 1995 se vaticinaba: que el cultivo de sorgo en el Meta tendería a desaparecer ${ }^{67}$. Parte de la responsabilidad se le atribuyó a los problemas de comercialización, precios y temporalidades de la cosecha.

Este último elemento fue central en las dificultades que enfrentaron los agricultores de cultivos semestrales en el Meta. En la medida en que el modo de desarrollo imponía el mercado como agente determinador de los precios, los ciclos de producción expusieron a los agricultores a caídas de precios en épocas de cosecha debido a que los productores del Meta se regían por las temporadas anuales climáticas; de allí que el mercado de sus productos estaba caracterizado por una salida masiva del mismo producto en corto lapso, lo que jalonaba la caída de los precios; y sin la intervención del Estado la situación empeoró. Esto indica que la implantación de un modo de regulación alejado de las particularidades contextuales afectó a los productores de cultivos semestrales de una forma definitiva. Los agricultores buscaron medidas del gobierno para reducir el impacto de la estacionalidad como los incentivos al almacenamiento ${ }^{68}$.

Figura 4. Trayectoria del sorgo en el Meta por hectáreas

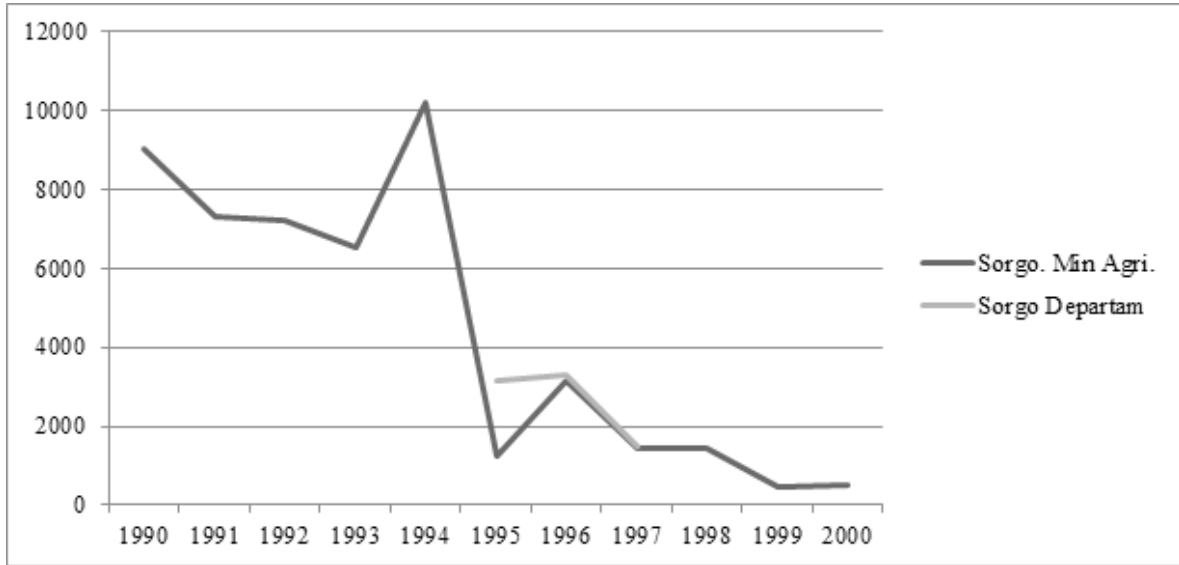

Fuente: Anuario estadístico Ministerio de Agricultura e informes de coyuntura del departamento.

${ }^{66}$ Urpa del Meta, Informe de coyuntura agrícola. 1991 B definitiva. Preliminar 1992,s. p.

${ }^{67}$ Cifras del Sector Agropecuario. 1995B Definitivo. Pronóstico 96A. Óp. Cit. 7.

${ }^{68}$ Entrevista a Eudoro Álvarez y Álvaro Orjuela. 


\section{Algodón}

El algodón se empezó a consolidar como posible cultivo para el segundo semestre desde inicios de la década de $1990^{69}$. El comportamiento descrito en la Figura 5 se debió a las bajas expectativas de negocio por parte de los agricultores frente a esta fibra ${ }^{70}$. El repunte de mitad de la década obedeció a las señales que el mercado estaba enviando y que el gobierno transmitió a los agricultores. Este escenario prometedor fue rápidamente confrontado por la realidad externa a las señales del mercado. En la comercialización, los industriales textiles adujeron que la fibra llanera presentaba inmadurez ${ }^{71}$. Ante la acción de los agentes económicos y las distorsiones internas de la comercialización, los productores de algodón se vieron seriamente golpeados y el gobierno obligado a subsidiar parte del precio de la fibra que se había acordado con los industriales y que estos no cumplieron. Como era lógico, los agricultores disminuyeron el área sembrada entre 1996-97 (Gráfico 3); la situación empeoró cuando la planta desmotadora que existía en Villavicencio fue trasladada al Casanare ${ }^{72}$. Esto, por supuesto, subió los costos de flete y producción, lo cual llevó a que en el último tercio de la década el algodón alcanzara un máximo de 500 hectáreas de cultivo.

Figura 5. Trayectoria del algodón en el Meta por hectáreas

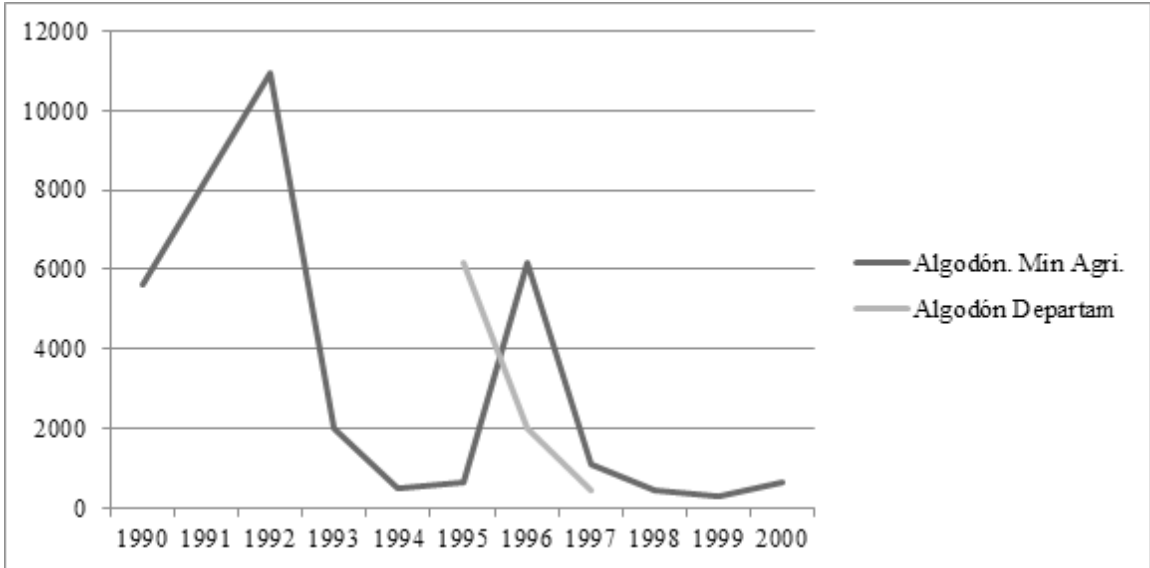

Fuente: Anuario estadístico Ministerio de Agricultura e informes de coyuntura del departamento.

${ }^{69}$ Informe de coyuntura Agrícola 1991 B Definitiva Preliminar 1992. Óp. cit. Documento sin Paginar.

${ }^{70}$ Minagricultura, Cifras del sector agropecuario. 1995B definitivo. Pronóstico 96A.

${ }^{71}$ Minagricultura, Cifras del sector agropecuario. 1997A definitivo. 1997B preliminar. 1998A pronóstico.

${ }^{72}$ Ibíd. 


\section{Cultivos anuales y permanentes}

En el departamento del Meta se distinguen varios cultivos de carácter anual o permanente, que han sido importantes en la economía agrícola de la región. La importancia de estos cultivos radica en que contribuyen tanto a la economía agrícola comercial o empresarial como a la economía campesina. De esta manera, el desempeño de cada tipo de cultivo, en virtud del modo de desarrollo, tuvo particularidades, apoyos y sesgos, en la política económica, que buscaron el favorecimiento de ciertos productos en virtud de la reafirmación del modelo agrícola en la apertura.

Los cultivos anuales a inicios de la década del noventa eran principalmente yuca y plátano. La yuca, en mayor medida de economía campesina, fue, como se verá, el refugio de los agricultores ante la presión de la apertura. El plátano estuvo asociado tanto a los cultivos comerciales o empresariales como a la economía campesina. Los permanentes eran la caña, el café, el cacao y la palma africana. Los tres primeros estaban relacionados, al igual que el plátano, tanto con la economía campesina como con la empresarial. La palma, por su parte, fue un cultivo más de economía empresarial pues demandaba grandes extensiones e intensidad en capital.

\section{Yuca}

Este cultivo estuvo asociado principalmente a la economía campesina en transición. A comienzos de la década del noventa se buscó implementar procesos de industrialización que hicieran más eficiente la producción, pero la inestabilidad de la comercialización impidió la consolidación de esta idea ${ }^{73}$. Esto explica el descenso de área cultivada entre 1990 y 1991, luego del cual la producción se mantuvo relativamente estable hasta mediados de la década. La crisis de la apertura no golpeó a los productores de yuca, en parte porque no estuvieron sometidos a las presiones internacionales.

Hacia 1995 se registró, según datos del Ministerio de Agricultura, un crecimiento inesperado del área cultivada en yuca en el Meta (Figura 6). Ese crecimiento importante no se refleja en las cifras que se manejaron departamentalmente, que no solo no registraron un avance similar, sino que mostraron un descenso. Esta disparidad se mantuvo en la segunda mitad de la década, lo que muestra un contraste entre lo alentador del Ministerio frente a la mirada propia del departamento.

${ }^{73}$ Urpa del Meta, Informe de coyuntura agrícola. 1991 B definitiva. Preliminar 1992. s. p. 
Figura 6. Trayectoria de la yuca en el Meta por hectáreas

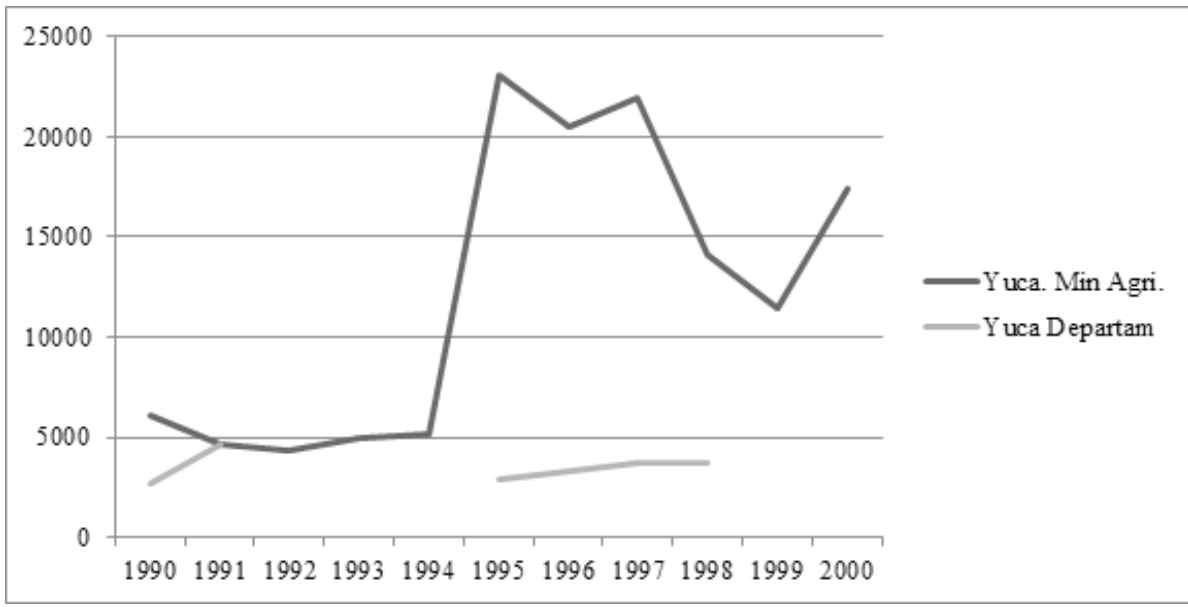

Fuente: Anuario estadístico Ministerio de Agricultura e informes de coyuntura del Departamento

Estas cifras no indican un rezago del cultivo. De hecho, hacia mediados de la década, los agricultores buscaron generar cadenas productivas a partir de la tecnificación y la integración vertical con la ayuda del gobierno. A pesar de que la yuca funcionaba en la economía campesina como un cultivo de colonización, similar al maíz tradicional, varias hectáreas de yuca se destinaron a la agroindustria ${ }^{74}$. La disparidad en las cifras podía responder al interés del Ministerio de mostrar resultados de sus políticas de promoción.

\section{Plátano}

En este cultivo anual el área cultivada se puede diferenciar entre la primera y la segunda mitad de la década.

Las razones para el dinamismo hasta 1995 no fueron las acciones propias del mercado, como lo quisieran los ideólogos del modo de desarrollo que rigió la década; de hecho, el comportamiento del cultivo se explica por diferentes razones. Por un lado, la mejora de los precios al productor, junto con los aportes en técnica que aportó el ICA, sumados al manejo empresarial del cultivo ${ }^{75}$, lo que muestra que las mejoras productivas eran el resultado de unas variables asociadas al mercado y otras que no. En este caso la acción de los agricultores y el acento empresarial que le dieron al cultivo jugaron un papel definitivo junto con

\footnotetext{
${ }^{74}$ Minagricultura, Cifras del sector agropecuario. 1995B definitivo. Pronóstico 96A.

${ }^{75}$ Urpa del Meta, Informe de coyuntura agrícola. 1991 B definitiva. Preliminar 1992. s. p.
} 
los aportes en tecnología ofrecidos por el ICA. El referido acento empresarial no significa que se pasó a un cultivo de tipo empresarial, intensivo en capital y de gran extensión, pues la mayoría de los cultivadores de plátano en el Meta eran pequeños y medianos productores que organizaron su producción desde el manejo de cuentas, libros, ingresos y egresos. Se comprobó entonces que la acción conjunta del Estado, los agricultores y la estabilidad de los precios permitirían mejoras productivas; hipótesis que otros autores han manejado para casos de mayor magnitud geográfica ${ }^{76}$

Fue tan importante el desempeño del sector productivo del plátano que hacia mediados de la década se duplicaron las hectáreas cultivadas (Figura 7). En 1996 se dio el primer retroceso del área cultivada en plátano, debido principalmente al ataque de la sigatoka ${ }^{77}$, enfermedad producida por un hongo que ataca las hojas, que hizo incrementar los costos de producción y reducir el cultivo, pues los rendimientos bajaron en un 50\%. La incertidumbre debida a la enfermedad redujo el ritmo de crecimiento del cultivo, pero no generó una caída en los primeros años posteriores. Así, hacia 1997 aún se mantenía el área. La enfermedad empezó a tener consecuencias significativas a partir del año 98 cuando su expansión había sido mayor, razón por la cual el cultivo cayó.

Lo anterior permite ver que el plátano fue un cultivo que tuvo un comportamiento diferente a los demás analizados hasta el momento en la medida en que no entró en crisis a partir de las medidas de apertura. Sin embargo, al cierre de la década se enfrentó a una reducción sustancial de su área ocupada por razones fitosanitarias y no a consecuencia de la política económica de apertura.

\footnotetext{
${ }^{76}$ Jorge Katz y Giovanni Stumpo, "Regímenes competitivos sectoriales, productividad y competitividad internacional," Series Desarrollo Productivo. Cepal 103 (2001).

${ }^{77}$ Minagricultura, Cifras del sector agropecuario. 1995B definitivo. Pronóstico 96A.
} 
Figura 7. Trayectoria de plátano en el Meta por hectáreas

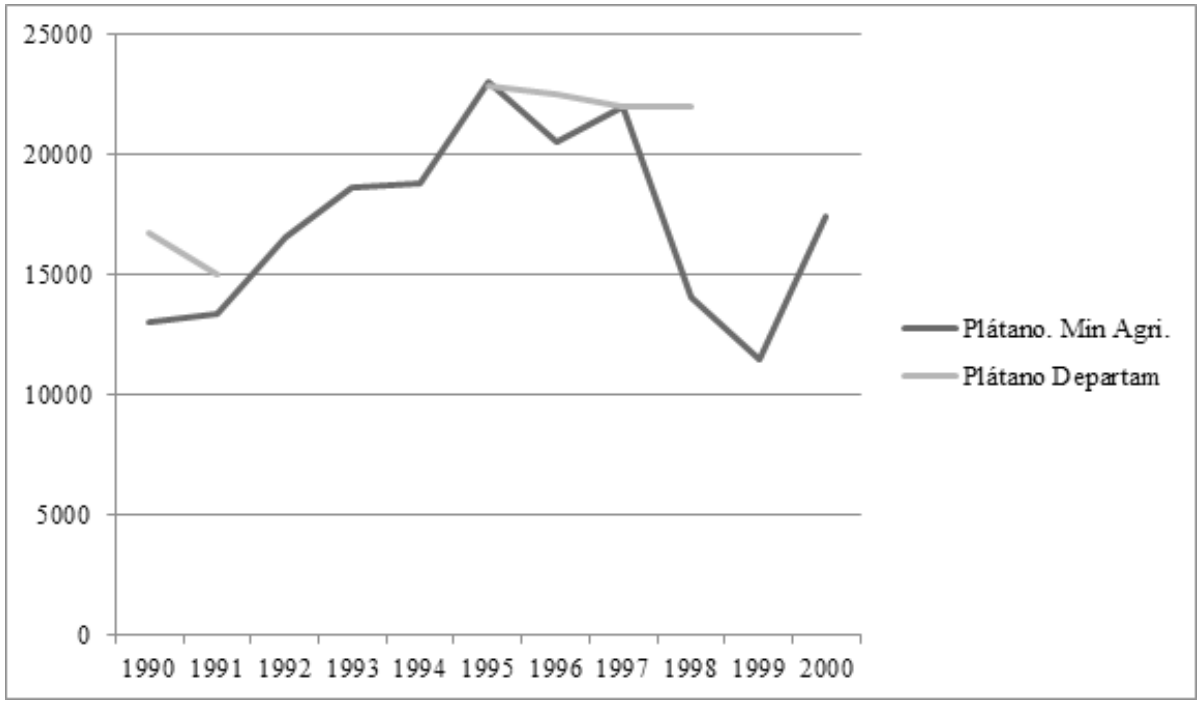

Fuente: Anuario estadístico Ministerio de Agricultura e informes de coyuntura del departamento.

\section{Caña}

La caña fue un cultivo permanente relativamente marginal en comparación con los descritos hasta el momento. Fue un producto principalmente campesino y su cultivo fomentó la formación de microempresas campesinas comunitarias alrededor de trapiches para la producción de panela, y como complemento de la canasta básica campesina ${ }^{78}$.

El área sembrada se mostró irregular durante la década, registrando ascensos y caídas. Esta irregularidad indica que el cultivo, aun siendo de economía campesina, también estuvo sujeto a la tendencia que marcó la política económica y la acción de fomento. Se podría pensar que, por ser un cultivo puramente campesino, su siembra partía de la iniciativa individual y no estaba marcada por las exposiciones al mercado; pero programas de fomento, como el proyecto de los trapiches comunitarios, incentivaron el cultivo. Luego el abandono del programa, por la falta de voluntad política para su sostenimiento, generó desestímulo ${ }^{79}$, lo que indica que aun en la economía campesina de subsistencia la acción del Estado era fundamental. En contraste, la prioridad que

${ }^{78}$ Minagricultura, Cifras del sector agropecuario. 1995B definitivo. Pronóstico 96a, , p. 10

${ }^{79}$ Minagricultura, Cifras del sector agropecuario. 1997A definitivo. 1997B preliminar. 1998A pronóstico. 
se le dio en la política económica al fomento de cultivos transables, a productos con vocación empresarial y el fomento a los cultivos con potencial exportador golpearon las posibilidades de subsistencia del campesinado que podía tener dinamismo si contaba con fomento por parte del Estado.

\section{Café y cacao}

El café en el Meta contó con una valoración marginal desde el Ministerio siendo un producto para cuyo cultivo se había ocupado un área importante. En los registros del Ministerio no se encuentra una cuantificación del cultivo para todo el departamento. Sin embargo, lo que muestran los datos reportados por el departamento es que su cultivo fue más importante, en términos de área cultivada, que el de la caña o incluso que el cacao.

Al inicio de la década este cultivo permanente comprendía un área de 15.000 hectáreas, cuando el país afrontaba una crisis cafetera de la que no se escaparon los metenses ${ }^{80}$. Así, entre 1990 y 1991 el área cayó en un 37.5\%. Descenso que también se registró en los rendimientos. Los informes de coyuntura y las evaluaciones agrícolas responsabilizaron a la apertura, a los problemas de precios internacionales y de comercialización como elementos centrales en la crisis.

Hacia finales de la década el cultivo, aunque mostraba signos de recuperación, no logró recobrar el área alcanzada a inicios de1990. Esto ilustra lo que constituyeron las promesas incumplidas por el nuevo modelo. El café se consideró como un cultivo con evidentes ventajas competitivas, pero la exposición al mercado (no solo de productos, sino cambiario) mermó la actividad cafetera en el Meta y llevó a los cultivadores a una crisis de la que no les fue posible salir durante la década entera.

\section{Cacao}

Este producto venía siendo fomentado por la regional de la Federación Nacional de Cacaoteros, pero los resultados fueron negativos desde $1988^{81}$. En esta coyuntura de finales de los ochenta se pasó de 8.500 hectáreas a 6.000 entre 1987 y 1988. Además, la apertura trajo problemas de comercialización y mercadeo, lo que aceleró su caída, como se muestra en la Figura 8. Las cifras del Ministerio registraron un descenso sostenido de la siembra año tras año en

${ }^{80}$ Urpa del Meta, Informe de coyuntura agrícola 1991 B definitiva. Preliminar 1992. s. p.

${ }^{81}$ Gobernación del Meta, El desarrollo agrícola en el Meta y la reciente coyuntura, p. 39, Cuadro 15. 
el periodo de 1991-1995. Aunque la mitad de la década fue un lapso en el que algunos cultivos registraron algo de recuperación, el cacao, por lo contrario, experimentó una caída sostenida durante el resto de la década.

Este cultivo se vio afectado por dos elementos determinantes: por un lado, la apertura y el cambio del modo de desarrollo que implicó cambios en la comercialización y que afectó su producción y, por otro, problemas fitosanitarios y el ataque de plagas ${ }^{82}$. De esta forma, el cacao fue uno de los cultivos que mayor retroceso tuvo durante la década en el departamento.

Figura 8. Cantidad de hectáreas sembradas con café y cacao en el Meta

\begin{tabular}{|c|c|c|c|c|c|}
\hline Año & $\begin{array}{l}\text { Cifras café } \\
\text { Minagricultura }\end{array}$ & $\begin{array}{l}\text { Cif ras cacao } \\
\text { Miagricultura }\end{array}$ & Año & \begin{tabular}{|l} 
Cifras café \\
departamentales
\end{tabular} & $\begin{array}{l}\text { Cifras cacao } \\
\text { departamentales }\end{array}$ \\
\hline 1990 & & 6.600 & 1990A & 15.565 & 6.500 \\
\hline 1991 & & 4.822 & 1991 & 9.962 & 7.003 \\
\hline 1992 & & 1.682 & & & \\
\hline 1993 & & 1.402 & & & \\
\hline 1994 & & 1.892 & $\begin{array}{c}\text { 1995A } \\
\text { Def. }\end{array}$ & 6.859 & 1.500 \\
\hline 1995 & & 1.300 & $\begin{array}{c}\text { 1995B } \\
\text { Def }\end{array}$ & 7.233 & 1.035 \\
\hline 1996 & & 897 & $\begin{array}{c}\text { 1996A } \\
\text { Pronos. }\end{array}$ & & \\
\hline 1997 & & 448 & $\begin{array}{c}\text { 1996B } \\
\text { Pronos. }\end{array}$ & & \\
\hline 1998 & & 367 & $\begin{array}{c}\text { 1997A } \\
\text { Def. }\end{array}$ & 8.475 & 448 \\
\hline 1999 & & 412 & $\begin{array}{l}\text { 1997B. } \\
\text { Prelim. }\end{array}$ & & \\
\hline 2000 & & 429 & $\begin{array}{c}1998 \\
\text { Pronos. }\end{array}$ & 9.400 & 448 \\
\hline
\end{tabular}

Fuente: Anuario estadístico Ministerio de Agricultura e informes de coyuntura del Departamento ${ }^{83}$.

${ }^{82}$ Minagricultura, Cifras del sector agropecuario. 1997A definitivo. 1997B preliminar. 1998A pronóstico, p. 5 .

${ }^{83}$ El Ministerio no cuenta con registros del cultivo de café para esta década en el departamento del Meta 


\section{Palma africana}

Fue uno de los cultivos permanentes más importantes en el departamento y afrontó dificultades por precios y costos de producción, como los demás productos. Pero algunas fuentes mencionaron otros problemas que, hasta el momento, no habían sido considerados para los otros cultivos, como la falta de garantías para exportar y la seguridad ${ }^{84}$. El hecho de que el problema de la exportación se mencione exclusivamente en relación con la palma no indica necesariamente que los demás cultivos no tenían vocación de exportación, pero sí que el énfasis exportador estaba concentrado en ese producto.

Lo cual muestra que, cuando los sucesivos gobiernos nacionales hablaron del énfasis exportador, empresarial y de ventajas comparativas, fue la palma africana el producto en el cual ese discurso tomó materialidad en escenarios específicos como el Meta. También se hizo evidente una narrativa oficial positiva, pues sobre la palma se consideraba que En el Meta se ha logrado mantener su ritmo de expansión, gracias a la consolidación y empeño de los cultivadores y las grandes empresas que han crecido con las bondades del cultivo y las ventajas que representa geo-estratégicamente $[. . .]^{85}$. Se nota entonces la confluencia de discursos que, tanto en el modelo de desarrollo como en la representación que desde las entidades del departamento, se hacían del cultivo y su empresariado. Narrativa ausente en todas las referencias para otros productores agrarios ${ }^{86}$.

La seguridad fue otro elemento señalado como problemático frente al producto, pero no fue mencionado como un problema para los demás cultivos. Ante esto se podría pensar que estos cultivos no fueron objeto de intimidación, amenazas o acciones directas por parte de los actores armados. La inclusión de la seguridad como un problema para este cultivo, y no para los demás, revalúa la percepción tradicional según la cual fue la seguridad la que desestimuló la inversión agrícola en el departamento Así, y bajo esta lógica, siendo que la palma estuvo más expuesta a los problemas de seguridad -como lo suponen las fuentes-su desempeño tendría que haber sido tan deficitario como el de los demás cultivos o aun más. A partir de las cifras se considerará esta hipótesis.

Como se mencionó, la palma era el principal cultivo permanente del Meta. Esto es verificable en el Figura 9; aun con las diferencias en los reportes, la

\footnotetext{
${ }^{84}$ Urpa del Meta, Informe de coyuntura agrícola. 1991 B definitiva. Preliminar 1992, s. p. 85 . Ibíd.

${ }^{86}$ Ver documentación de la década correspondiente a evaluaciones agrícolas o a informes de coyuntura en la Colección Corpes de la Biblioteca Luis Ángel Arango.
} 
palma era por mucho el cultivo permanente con mayor área sembrada, y fue de los pocos que, en los dos primeros años de la apertura, creció su área cultivada.

Figura 9. Trayectoria de la palma africana en el Meta por hectáreas

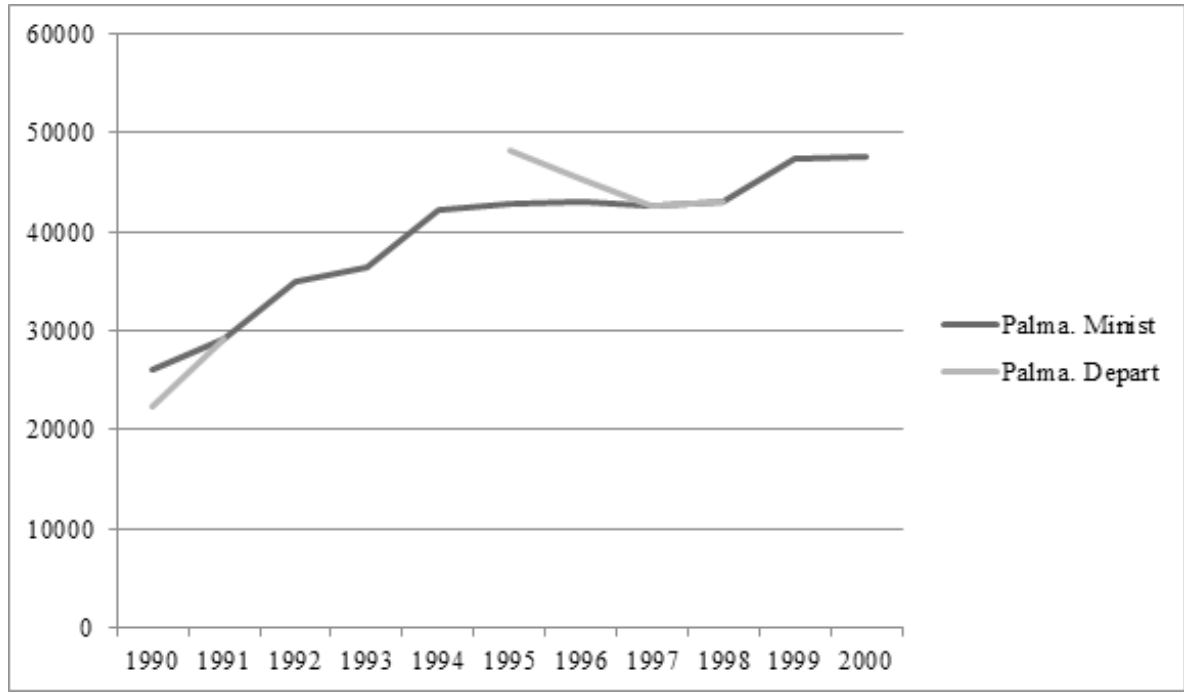

Fuente: Anuario estadístico Ministerio de Agricultura e informes de coyuntura del departamento.

La apertura también se vio como una amenaza debido a que el cambio del modo de regulación develó las falencias que había en el almacenamiento, la sobreoferta, los oligopolios en la industria de aceites e incoherencias en la política arancelaria; señalados como elementos contradictorios para los palmeros. No obstante, el ritmo de crecimiento del cultivo era sostenido. Los mismos problemas que afectaron a los demás cultivadores no perjudicaron a los productores de la oleaginosa. De hecho entre 1990 y 1992 aumentó el área cultivada, con. Un desempeño muy destacado en comparación con los demás.

Para el año 1995 había aumentado aún más y se consideró que en la mayoría de los terrenos sembrados con palma se estaba sustituyendo al arroz que se estaba desestimulando. Esta afirmación no es coherente con las cifras reportadas por las autoridades del departamento, pues se puede ver que el arroz de riego mantiene su área entre 1991-95 mientras que la palma crece en 25 mil hectáreas. Ya se mencionó que eventualmente estos cultivos podrían competir por las condiciones de los terrenos.

En los años 96, 97 y 98, se estabilizó el cultivo, y creció a ritmos menores de los que venía mostrando, sin que fuera problemática su situación. Así, la 
evaluación agrícola del 97 muestra exactamente la misma narrativa que la del 91. Es decir que pareciera que el gran aumento del cultivo no implicó mayor interés por parte de las autoridades, en contraste con otros cultivos en los que la evaluación registra el desempeño, las enfermedades, la comercialización, etc. Este desinterés por explicar la dinámica del cultivo que se presentó en las autoridades permite ver que se evitó que las razones del desempeño de ese cultivo fueran de manejo público. En los últimos años de la década el cultivo crece, pero a un menor ritmo del registrado a comienzos de la misma.

\section{Conclusión}

En este texto se ha mostrado cómo los tres gobiernos nacionales de la década del noventa tuvieron diferentes formas de abordar el desarrollo económico agrícola, pero una constante general fue la persistencia en el modelo de un desarrollo guiado por las exportaciones. Así, el modo de regulación fue establecido y en ocasiones profundizado. Se puede apreciar que la adhesión al régimen internacional fue un imperativo económico sin evaluar las particularidades regionales y que se reflejó en el ámbito del departamento del Meta. Los gobiernos departamentales, a su vez, apelaron al discurso de las ventajas comparativas y competitivas para la inserción en los mercados internacionales. Sin embargo, los impactos negativos de la apertura en la agricultura del departamento llevaron en su momento a que la dirigencia departamental criticara la reducción en la capacidad de acción por parte del Estado frente a la producción.

La apertura generó efectos negativos en los cultivos del departamento en general. Los cultivos semestrales se vieron afectados por variables como el crédito y las importaciones. También, al ser el mercado el regulador de la economía, los precios fueron más vulnerables debido a la estacionalidad de los cultivos semestrales. Esta investigación analizó algunas fuentes que permitieron ver las dinámicas del cultivo, pero una exploración de otras fuentes, tales como archivos privados de los agricultores, podrían ayudar a comprender mejor estas dinámicas.

Se puede establecer que el proceso de reforma estructural establecido en Colombia desde la década del noventa generó cambios importantes en la economía agrícola del Meta. El segmento que había hecho tránsito hacia cultivos semestrales, buscando un mayor flujo de ingresos para los productores, fue el más afectado por la apertura en la medida en que en el mercado interno compitieron con producción importada. La exposición a los precios 
internacionales (distorsionados por los subsidios) generó dificultades para los productores del Meta en el contexto de la globalización.

Los cultivos propios de la economía campesina como el cacao, la caña y el café, sufrieron, en el marco de la apertura, un descuido casi absoluto por parte de la política económica. Solo se pudieron mantener en la medida en que no estuvieron expuestos a las presiones del mercado (excepto el café), pero su desempeño positivo y su avance estuvieron relegados por la falta de atención. Al contrario de los cultivos de tipo campesino, la palma fue beneficiaria de la política pública de fomento lo que ayudó a que su crecimiento en extensión fuera destacado.

\section{Referencias bibliográficas}

\section{Fuentes primarias}

\section{Impresas}

\section{Publicaciones periódicas}

Gaceta del Meta, n. . 1.021 , octubre 13 de 1995; n. ${ }^{\circ} 1.105$, agosto 10 de 1998.

\section{Publicaciones no periódicas}

Consejo Regional de Planificación Social y Económica de la Orinoquia, Corpes Orinoquia. Diagnóstico integral de la Orinoquia colombiana. Anexo Estadístico.Villavicencio; 1993. Colección Corpes, Biblioteca Luis Ángel Arango.

Departamento Nacional de Planeación (DNP Umacro, Uda) y Ministerio de Agricultura y Desarrollo Rural. "Instrumento de franjas de precios para la importación de productos agrícolas y subproductos seleccionados”. Documento DNP 2511. Bogotá: febrero de 1991.

Gobernación del departamento del Meta. Plan de desarrollo integral: "Nuestra meta es el Meta"1993-1997. Villavicencio: 1993.

Gobernación del Meta, Secretaría de Agricultura, Ganadería y Desarrollo. El desarrollo agrícola en el Meta y la reciente coyuntura. Villavicencio: 1989. Colección Corpes, Biblioteca Luis Ángel Arango.

Ministerio de Agricultura y Desarrollo Rural, y Departamento Nacional de Planeación, DNP. Estrategias y políticas para el desarrollo agropecuario 1990. Bogotá: 1990.

Ministerio de Agricultura y Desarrollo Rural, y Secretaría de Agricultura del departamento del Meta. Cifras del sector agropecuario 1995... Villavicencio: enero de 1996. Colección Corpes, Biblioteca Luis Angel Arango.

Ministerio de Agricultura y Desarrollo Rural, y Secretaría de Agricultura del departamento del Meta. Cifras del sector agropecuario. 1995B definitivo. pronóstico 96A. Villavicencio: enero de 1996. Colección Corpes, Biblioteca Luis Ángel Arango.

Ministerio de Agricultura y Desarrollo Rural, y Secretaría de Agricultura del departamento del Meta. Cifras del sector agropecuario: 1997A definitivo. 1997B preliminar. 
1998A pronóstico. Villavicencio: Enero de 1998. Colección Corpes, Biblioteca Luis Ángel Arango.

Ministerio de Agricultura y Desarrollo Rural. Anuario estadístico del sector agropecuario. 1993-1994. Santafé de Bogotá. 1995. Disponible en Biblioteca del Ministerio.

Ministerio de Agricultura y Desarrollo Rural. Avances de la política sectorial en la región de la Orinoquia.Santafé de Bogotá: Ministerio de Agricultura y Desarrollo Rural, septiembre de 1997.

Ministerio de Agricultura y Desarrollo Rural. El balance del sector agropecuario en 1993. La política de reactivación y sus frutos. Bogotá: Minagricultura, diciembre de 1993.

Secretaría de Agricultura, Ganadería y Desarrollo del departamento del Meta. El desarrollo agríicola en el Meta y la reciente coyunturaVillavicencio: junio 1989. Colección Corpes, Biblioteca Luis Ángel Arango.

Unidad Regional de Planificación Agropecuaria del Meta, Urpa del Meta. Análisis de coyuntura agrícola. Primer semestre 1990. Cultivos semestrales. Federación Nacional de Arroceros,Fedearroz.Villavicencio: junio de 1990. Colección Corpes, Biblioteca Luis Ángel Arango.

Unidad Regional de Planificación Agropecuaria del Meta, Urpa del Meta. Informe de coyuntura agrícola 1991 B definitiva, preliminar 1992. Villavicencio: 1992. Colección Corpes, Biblioteca Luis Ángel Arango

\section{No impresas (digitales)}

Departamento Nacional de Estadística, Dane. Cuentas departamentales - Colombia. S.f. Bogotá: archivo digital en la biblioteca nacional del Dane, consultado: Agosto de 2014 .

Federación Nacional de Arroceros,Fedearroz. Estadísticas arroceras. Importaciones de arroz a Colombia 1990-2000, consultada en 13 de diciembre de 2017, http://www. fedearroz.com.co/new/importaciones.php

Departamento Nacional de Planeación, DNP. Plan nacional de desarrollo 1990-1994. La revolución pacífica,https://www.dnp.gov.co/PND/PlanesdeDesarrolloanteriores.aspx

Departamento Nacional de Planeación, DNP. Plan nacional de desarrollo 1994-1998. El salto social, https://www.dnp.gov.co/PND/PlanesdeDesarrolloanteriores.aspx

Departamento Nacional de Planeación, DNP. Plan nacional de desarrollo 1998-2002. Cambio para construir la paz, https://www.dnp.gov.co/PND/PlanesdeDesarrolloanteriores.aspx

\section{Fuentes secundarias}

Antonio, OcampoJosé, and Leonardo Villar. “Trayectoria Y Vicisitudes de La Apertura Económica Colombiana." Pensamiento Iberoamericano, no. 21 (1992): 165-86.

Baena Rojas, Jose Jaime, and Xavier Fernández Pons. "Aproximaciones A La Inserción De Colombia En El Sistema Multilateral De Comercio En 1995-2015." Análisis Político 29, no. 87 (2016): 114-31. 
Balcázar V, Álvaro. “La Agricultura Colombiana Y Las Políticas de Apertura Económica." Coyuntura Agropecuaria 10 No 3 (1993): 93-104.

Bonilla González, Ricardo. “Apertura Y Reprimarización de La Economía Colombiana." Nueva Sociedad 231 (2011): 46-65.

Estrada Álvarez, Jairo. "Orden Neoliberal Y Reformas Estructurales En La Decada de 1990: Un Balance Desde La Experiencia Colombiana." Ciencia Política, no. 1 (2006): 141-78.

Garay, Javier. “La Política de Inserción Internacional de Colombia." Nueva Sociedad 231 (2011): 66-78.

García Gutiérrez, Emilio. La Apertura Y El Agro En El Meta 1990-1994. Santafé de Bogotá: Produmedios., 1995.

Gómez Ávila, Gabriel Enrique. "Análisis de La Implementación de Las Políticas Neoliberales En Colombia. El Caso de La Agroindustria Comercial de La Palma Africana." Colegio Mayor de Nuestra Señora del Rosario, 1996.

Hernández, Gustavo Adolfo., and Juan Ricardo Perilla. "Análisis de Las Importacione Agropecuarias En La Década Del 90.” Bogotá, 2001.

Jaramillo, Carlos Felipe. Crisis Y Transformación de La Agricultura Colombiana 19902000. Bogotá: Banco de la República, Fondo de Cultura Económica, 2002.

Kalmanovitz, Salomón, and Enrique Lopez. La Agricultura Colombiana En El Siglo XX. Bogotá: Fondo de Cultura Económica, Banco de la República, 2006.

Katz, Jorge, and Giovanni Stumpo. "Regímenes Competitivos Sectoriales, Productividad Y Competitividad Internacional." Series Desarrollo Productivo. CEPAL 103 (2001).

López Pineda, Luis Fernando. “Transformación Productiva de La Industria En Colombia Y Sus Regiones Después de La Apertura Económica." Cuadernos de Economía 29, no. 53 (2010): 239-86.

Méndez, Diana Marcela. "The Impact of Economic Liberalization on Gender Equality in Colombia." CS Ciencias Sociales, no. 15 (2015): 145-71.

Misas Arango, Gabriel. La Ruptura de Los 90. Del Gradualismo Al Colapso. Bogotá: Universidad Nacional de Colombia., 2002.

Rodrik, Dani. “Poor Countries in a Rich World." In The GLobalization Paradox. Democracy and the Future of the World Economy. New York, London.: Norton, 2011. 